\title{
Graduação e pós-graduação em Farmácia no Brasil: convergências e fortalecimento de capacidades
}

\author{
Undergraduate and postgraduate pharmacy courses in Brazil: convergences and strengthening of capacities
}

\author{
Graduación y postgrado en Farmacia en Brasil: convergencias y fortalecimiento de capacidades
}

Nos últimos anos, as Ciências Farmacêuticas têm evoluído expressivamente como área de interesse nacional, seja pela sua influência no setor produtivo, seja como direito social à saúde, mas, também, como campo de investigação de grande impacto e como área em constante expansão na formação graduada e pós-graduada.

Durante o I Congresso da Associação Brasileira de Ciências Farmacêuticas (ABCF) (disponível em: <http://www.abcfarm.org.br/>), ocorrido em outubro de 2012, em Pernambuco, membros da sociedade científica das ciências farmacêuticas reuniram-se para refletir sobre uma questão por muito tempo negligenciada no país: a busca de convergência das capacidades e necessidades da graduação e da pós-graduação em farmácia no contexto nacional. Durante três dias, representantes de instituições farmacêuticas, pesquisadores e coordenadores de cursos de graduação e de pós-graduação debateram proposições iniciais com o objetivo de apresentar, para a comunidade acadêmica, possibilidades e desenvolvimento de estratégias que visam aperfeiçoar a formação, a pesquisa e o atendimento às necessidades sociais.

O contexto da formação na área farmacêutica da pesquisa e do setor farmacêutico no Brasil foi revisitado para nortear discussões, considerando sobretudo:

- as mudanças no ordenamento da educação no Brasil, a partir da constituição de 1988, e, especialmente, com a LDB, de 1996 (Brasil,
1996), instituindo o fim dos currículos mínimos, a autonomia universitária, a flexibilização e liberalização do setor, permitindo que a lógica da competitividade de mercado exerça maior poder sobre a regulação dos cursos de graduação que o próprio Estado;

- a determinação de um âmbito privativo para a atuação do profissional farmacêutico em 1981, pelo Decreto n.85.878 (Brasil, 1981), com as atividades relativas aos medicamentos (produção, manipulação, dispensação, distribuição, pareceres técnicos, fiscalização e ensino) definidas como atividades exclusivamente farmacêuticas, enquanto outros campos de atuação como compartilhados com outros profissionais, não exclusivos do farmacêutico (mais de 70 campos de atuação definidos por resoluções do Conselho Federal de Farmácia, incluindo: as análises clínicas e bromatológicas, a cosmetologia, o controle ambiental etc.):

- as Diretrizes Curriculares para os Cursos de Farmácia (Brasil, 2002), que estabeleceram o objetivo da formação do farmacêutico como profissional de saúde preparado para atuar no sistema de saúde brasileiro, e sobre as necessidades sociais do país, gerando grande movimento de discussão e modificação curricular nos cursos de graduação;

- dados sobre a formação farmacêutica, indicando o número de 444 cursos de farmácia em atividade no país, o crescimento exponencial da oferta de vagas, especialmente em instituições 
privadas, a partir de 1996, e a iniquidade de oferta de vagas entre as regiões brasileiras (Conselho Federal de Farmácia, 2012);

- o diagnóstico de que há grande distanciamento entre realidade social e a academia, comprometendo a educação para a cidadania e a formação de profissionais competentes para atuar com integralidade sobre a complexidade social (Brasil, 2008; Leite et al., 2008);

- o crescimento do número de cursos de graduação em Farmácia, indicando uma demanda por formação de docentes de nível superior na área;

- o crescimento significativo da pós-graduação em Farmácia no Brasil, que chega a 56 programas em 2012;

- a extrema disparidade entre os sistemas de avaliação e regulação para a graduação (INEP) e pós-graduação (Capes), desenvolvendo muito maior dedicação do corpo docente das unidades acadêmicas à última;

- a disparidade da valorização, dentro e fora das universidades, das atividades docentes relativas à graduação e à pós-graduação.

A partir destas considerações iniciais, os participantes quedaram-se sobre algumas questões que merecem atenção no meio acadêmico da área da Farmácia:

- Como as diretrizes curriculares para os cursos de Farmácia têm refletido na pós-graduação da área?

- Como a Pós-graduação tem contribuído para a formação do farmacêutico crítico, reflexivo e preparado para atender as necessidades sociais para o desenvolvimento do Brasil?

- Em que e de que formas a pós-graduação e a graduação em Farmácia podem e devem convergir para ampliar e consolidar a área no país?

- Como a ABCF, representante do setor das ciências farmacêuticas no Brasil, pode colaborar neste sentido?

Com base nestas considerações e interrogações, com as experiências e expectativas dos participantes e a perspectiva de desenvolvimento de ações coordenadas pela $A B C F$, foram levantadas as proposições abaixo descritas:

1. Definir, após trabalhos conduzidos pela $A B C F$ - realizados juntamente com o Fórum de Coordenadores dos Cursos de Pós-graduação da Área da Farmácia na Capes, do Comitê de
Assessoramento da Farmácia no CNPq e da Coordenação da Área da Farmácia na Capes -, as diferentes subáreas para a área Farmácia, sinalizando e fomentando o desenvolvimento e valorização da diversidade de conhecimentos, práticas e necessidades que compõem a pesquisa e desenvolvimento da área, e que devem se refletir no processo de formação do profissional farmacêutico em todos os níveis;

2. Incentivar pesquisas sobre a educação e as demandas sociais na área farmacêutica para subsidiar definições políticas e regulatórias no setor saúde e no âmbito da educação profissional;

3. Buscar atuar junto aos órgãos de regulação da formação farmacêutica para colaborar com a qualificação do processo de avaliação e das políticas educacionais, com fins de garantir melhor qualidade da formação do profissional farmacêutico no país;

4. Colaborar ativamente com as instituições e os movimentos nacionais e internacionais pela qualificação da formação profissional em Farmácia;

5. Estimular a criação, no âmbito da ABCF, de núcleos de debate e de proposição de intervenções por tema de interesse dos pesquisadores, incluindo a questão do ensino e do desenvolvimento da graduação como parte inerente do desenvolvimento da área de pesquisa e de inovação tecnológica farmacêutica;

6. Induzir a realização de estratégias de formação complementar integradas entre pósgraduação e graduação, como as experiências já conhecidas das "escolas de inverno" ou "de verão" e os eventos acadêmicos integrados.

Outro conjunto de proposições foi elaborado com o objetivo de gerar ações coordenadas pelo Fórum de Coordenadores de Cursos de Pósgraduação na Área da Farmácia na CAPES, instância de interlocução entre os programas de pós-graduação, que vem discutindo e sugerindo ações relativas à área, especialmente quanto à regulação, avaliação e estratégias para o fortalecimento da pós-graduação na área. Sugere-se que o Fórum deva discutir e buscar desenvolver, no âmbito dos programas de pósgraduação em Farmácia, as proposições abaixo relacionadas:

1. Desenvolver atividades de extensão universitária, como: atividades destinadas à sociedade, que possam integrar as finalidades de interação e assistência para a população, campo de estágio e formação acadêmica, e campo e 
linha de pesquisa para a pós-graduação (a exemplo das farmácias-escolas, unidades hospitalares, programas desenvolvidos em diversos tipos de instituições);

2. Buscar formas de institucionalizar a oferta de disciplinas que possam ser validadas para a pósgraduação, a graduação e os programas de residência;

3. Desenvolver estratégias de planejamento de curto, médio e longo prazo que envolvam a graduação e a pós-graduação como um conjunto integrado e interdependente dentro das unidades acadêmicas e universidades;

4. Validar carga-horária de pesquisa para as atividades de iniciação de graduandos e de tutoria de iniciação científica para os pós-graduandos;

5. Buscar estratégias de integrar a formação e a pesquisa também com as áreas afins $d a$ Farmácia, para o desenvolvimento da pesquisa, da formação e ação interdisciplinar;

6. Discutir e apontar indicadores concretos e sensíveis da relação entre a graduação, a extensão e a pós-graduação para fins de avaliação e de norteamento das ações da pós-graduação em Farmácia;

7. Identificar os mecanismos existentes para fomentar e promover a formação docente para atender as necessidades do grande número de cursos de graduação em Farmácia no país;

8. Qualificar as atividades de Estágio de Docência, definindo, em sua ementa, o estudo do histórico e do contexto da educação farmacêutica no Brasil (Diretrizes Curriculares, Lei de Diretrizes e Bases da Educação, demandas sociais, avanços e desafios da área), justificando e embasando as atividades didático-pedagógicas propostas pelos pós-graduandos, pelos norteadores das Diretrizes
Curriculares e os Projetos Político-Pedagógicos dos cursos de graduação em que estão estagiando.

A iniciativa de levar, para o I Congresso da ABCF, a pauta da relação graduação-pósgraduação denota, claramente, a política proposta pela instituição de trabalhar pela valorização e desenvolvimento da área farmacêutica, e a compreensão de que a plena consolidação da pesquisa e da pós-graduação em farmácia depende de escolas de farmácia fortes, bem articuladas, estruturadas e formadoras de profissionais farmacêuticos altamente competentes e preparados para atuar na pesquisa, nos serviços, no mercado farmacêutico e na política de saúde brasileira.

A validade das proposições relatadas se dará na medida do comprometimento da categoria com a causa, transcrevendo, na prática da formação e da pesquisa nas instituições de ensino, o desejo e a certeza de que a educação farmacêutica pode crescer e gerar as respostas de que a sociedade necessita.

Por fim, espera-se que os pontos levantados sejam ingredientes para a construção de uma agenda estruturada para subsidiar o processo de formulação e avaliação de políticas e programas para a área farmacêutica no país.

Silvana Nair Leite

Departamento de Ciências Farmacêuticas, Universidade Federal de Santa Catarina. Campus Universitário Reitor João David Ferreira Lima, Trindade. Florianópolis, SC , Brasil. 88040-900. Silvana.nair@hotmail.com

Suely Lins Galdino Programa de Pós-Graduação em Inovação Terapêutica, Universidade Federal de Pernambuco. In memoriam.

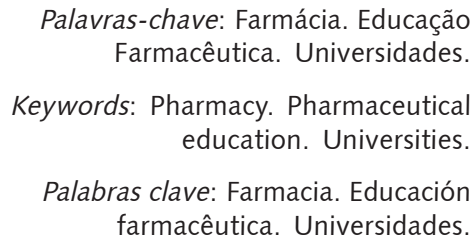

Palavras-chave: Farmácia. Educação Farmacêutica. Universidades.

Keywords: Pharmacy. Pharmaceutical education. Universities.

Palabras clave: Farmacia. Educación farmacêutica. Universidades. 
NOTAS BREVES

\section{Colaboradores}

Os autores participaram, igualmente, de todas as etapas de elaboração do artigo.

\section{Referências}

BRASIL. Ministério da Saúde. I Fórum Nacional de Educação Farmacêutica: o farmacêutico de que o Brasil necessita. Relatório final. Brasília: MS, 2008.

Resolução CNE/CES 2, de 19 de fevereiro de 2002. Institui Diretrizes Curriculares Nacionais do Curso de Graduação em Farmácia. Disponível em: <http://portal.mec.gov.br/cne/ arquivos/pdf/CES022002.pdf > . Acesso em: 10 jan. 2013.

Lei no 9.394, de 20 de dezembro de 1996. Estabelece as diretrizes e bases da educação nacional. Disponível em: < http:// portal.mec.gov.br/seed/arquivos/pdf/tvescola/ leis/lein9394.pdf>. Acesso em: 10 jan. 2013.

Decreto $n^{\circ} 85.878$, de 07 de abril de 1981. Estabelece normas para execução de Lei $n^{\circ}$ 3.820 , de 11 de novembro de 1960, sobre o exercício da profissão de farmacêutico, e dá outras providências. Disponível em <http:// www.planalto.gov.br/ccivil_03/decreto/Antigos/ D85878.htm > . Acesso em: 10 jan. 2013.

CONSELHO FEDERAL DE FARMÁCIA. VIII Encontro Nacional de Coordenadores de Cursos de Farmácia. Brasilia: CFF, 2012.

LEITE, S.N. et al. I Fórum Nacional de Educação Farmacêutica: o farmacêutico que o Brasil necessita. Interface (Botucatu), v.12, n.25, p.461-2, 2008. 